\title{
DETERMINANTS OF DIFFERENCES IN REGIONAL CYCLICAL VARIABILITY
}

\author{
Stefan C. Norrbin"
}

\section{Introduction}

The cyclical movement of macroeconomic variables indicates a relatively smooth process of adjustment to external shocks. The appearance of a unidirectional movement is less pronounced when disaggregated data are used. This observation was made in early work leading to a multitude of disaggregated business cycle theories by, for example, Schumpeter (1939), Hayek (1931) and Vining (1946). Some of these theories emphasized regional sources of the business cycle, while others emphasized industrial sources. Little empirical research has been devoted to testing these early theories of regional cyclical variability. The recent regional research by Browne (1978), Victor and Vernez (1981), Howland (1984) and Goldstein (1986) attempts to fill this void. However, the recent research either studies differences in specific downturns or looks at the sensitivity to exogenous shocks across regions in a time-series framework.

In this paper the problem is approached somewhat differently, in an attempt to test the difference in regional cycles directly. This approach permits testing whether specific characteristics inherent in a regional economy lead to higher or lower regional cyclical variability than in other regions. If such characteristics exist, states with higher or lower than average "natural" regional cyclical variability could be identified.

To be able to test directly some of the explanations for differences in magnitudes of business cycle variations between regions, the variance of the cyclical component of employment in each region is calculated. These estimates of regional cyclical variability can be used to test the theories of regional business cycles in a cross-sectional OLS approach.

The following section explains the hypothesis developed earlier by several authors but not yet tested. In section III the model used to estimate the cyclical variability is presented. In section IV the results are presented, and some conclusions and a brief discussion of the relevance of the findings are provided in section $\mathrm{V}$.

\footnotetext{
Assistant Professor of Economics, University of Alabama. The author is grateful for extensive disscussions with Lee McPheters, Bill Gunther and Walt Misiolek.
}

\section{Explanation of a Divergency in Regional Cyclical Variability}

A multitude of theories have been suggested to explain the differences observed across regions. ${ }^{1}$ The most obvious explanation invokes the structure of the industry of the region. If a region has a large share of its employment in a very volatile industry the aggregate variability of that region will be very large. This is known as a direct industry composition effect, and it can be eliminated by adjusting the regional variability to the national average structure instead of the structure of the region.

In addition to the direct industry composition effect Vining (1946a, 1946b) suggested that an indirect effect of the industrial structure may exist. He classified industries as "primary" or "export" oriented and "passive" local industries. The "primary" industry would be affected through inter-regional trade conditions and would dictate the behavior of other local industries. The local industries would adjust "passively" to the cycle of the "primary" or "carrier" industry. ${ }^{2}$ For example, if mining is a key sector in a region that industry would constitute a "primary" sector. If frequent exogenous shocks result in a highly variable mining industry, local "passive" industries also would be affected, and the result would be higher than average variability for all industries.

This "primary" industry argument obviously could increase or decrease variability in a state, depending on whether the "primary" industry is a highly variable or a less variable industry. To test this hypothesis, the explanatory power of four variables is investigated. Finance, Insurance and Real Estate (FIRE) and nondurable manufacturing represent the less variable industries; durable manufacturing and mining represent the highly variable industries.

A second hypothesis suggests that the growth rate of a state might influence the cyclical variance. Steiner (1949) argues that "conservative financial practice, a high propensity to save, a large body of unproductive consumers, and the desire for safe rather than speculative investment" (p. 133) make low growth states less sensitive to cyclical changes. The opposite influence of the growth rate has been argued by Borts (1960). "Greater cyclical amplitudes will be associated with pools of unemployed labor, with high cost production facilities, and with the declining 
segments of an industry" (p. 181). Peak-to-peak growth rates are used in this paper to test the effect of the growth rate on the cyclical variance of a state, using the definition of a business cycle peak proposed by the National Bureau of Economic Research. This measure was chosen as resources are fully utilized at the peaks of cycles and employment levels therefore can be compared across time. ${ }^{3}$ A third explanation for the regional divergence of variances cites the type of capital in place in particular states. It has been argued that old heavy capital tends to have more problems adapting to changing cyclical conditions, and causes larger cyclical swings in such states. ${ }^{4}$ The more easily adaptable capital stock of the "Sun-belt" states would be expected to result in lower than average cyclical fluctuations. To test this theory a binary variable indicating the presence or absence of a "Sun-belt" state was used."

A fourth hypothesis has been suggested by Goldstein (1986). He argues that some states are more sensitive to international fluctuations than to domestic fluctuations. The impact on the cyclical variance of a state can be positive or negative, depending on the covariation of domestic and international fluctuations. If the national economy has a negative covariance with international fluctuations, this international dependence will tend to lower the cyclical variance of the states more sensitive to international economic variation. To test this hypothesis, the export share of the manufacturing output in each state is used. ${ }^{6}$

These four hypotheses were tested using a log-linear functional form. Before turning to the results, the procedure for calculating the cyclical variability should be addressed.

\section{A Model of Cyclical Variability}

The cyclical variance is estimated using quarterly employment data from first quarter 1955 to fourth quarter 1984. The data are disaggregated by state and one-digit SIC code. The data are from the Labstat data base of the U.S. Bureau of Labor. ${ }^{7}$ For some states, the Labstat data base was incomplete. To complete the data set, individual states were contacted and the missing data were obtained from all states.

Before any estimation could be completed, it was necessary to calculate the cyclical component of the employment data. Many empirical studies of the business cycle deal with this problem by filtering the data with a deterministic time trend and seasonal dummy variables. Nelson and Plosser (1982) suggest that this procedure is likely to confound the growth and cyclical components in the series, overstating the magnitude and duration of the cycles.
Instead of using a deterministic filter this study followed the suggestion of Nelson and Plosser and allowed for a possible stochastic growth component and a seasonal component by first and fourth differencing the log of employment in each industry of each region. Performing this operation in a disaggregated fashion allowed for the possibility of changing growth and seasonal patterns across both time and industries. After the data are treated with this filter the remaining component is the cyclical component. $^{8}$

The cyclical component is a time-series for each industry in each region. These time-series were aggregated into a regional variance for each state according to the formula:

$$
\mathrm{Y}_{\mathrm{R}}=\mathrm{X}_{\mathrm{RI}} \mathrm{W}_{\mathrm{RI}}
$$

where R, I are the number of states and industries, respectively, $Y_{R}$ is a T X R matrix of aggregate employment by state over time, and $\mathrm{X}_{\mathrm{RI}}$ is a T X RI matrix of employment in each industry, by state, over time. From these two matrices $\mathrm{W}_{\mathrm{RI}}$, an RI X R matrix of weights, can be calculated. These weights represent the share of employment of an individual industry $i$ in a state $r$. To calculate the variances of state employment, the variance of $Y_{R}$ was estimated as follows:

$$
\mathrm{V}\left(\mathbf{Y}_{\mathbf{R}}\right)=\mathbf{W}_{\mathrm{RI}}^{\prime} \mathbf{V}\left(\mathbf{X}_{\mathrm{R}}\right) \mathbf{W}_{\mathrm{RI}}
$$

Equation (2) estimates the cyclical variability of employment in a given state $r$, by weighting the more important sectors more heavily and the less important sectors less heavily. The resulting variance is approximately the same as if the variance were calculated directly from the aggregate employment of the state, but the exposition facilitates discussion of a different weighting system below. The variances are presented in Table 1. Clearly, the variances in Table 1 are dissimilar. New York has the smallest cyclical variance of any state, while West Virginia has a cyclical variance 28 times as large. The obvious explanation for these differences in cyclical variation is the difference in the industrial structure of the states. If a state has a large share of its employment in a highly cyclical industry such as durable manufacturing this fact alone will make the aggregate cyclical variability appear large. 9 To eliminate this problem, the individual industry variances were reweighted according to:

$$
\mathrm{V}\left(\mathrm{Y}_{\mathrm{R}}{ }^{*}\right)=\mathrm{W}^{\prime}{ }_{\mathrm{NI}} \mathrm{V}\left(\mathrm{X}_{\mathrm{RI}}\right) \mathrm{W}_{\mathrm{NI}}
$$

where $\mathrm{W}_{\mathrm{NI}}$ is an RI X R matrix of average weights for the United States, and $Y_{R}{ }^{*}$ is the re-weighted regional variance for each state. The weights represent the share of an 
Table 1

Cyclical Employment Variability, by State, 1955-1984"

\begin{tabular}{llllll}
\hline \hline Rank & State & Variance & Rank & State & Variance \\
\hline 1 & New York & 0.000058 & 25 & Louisiana & 0.000147 \\
2 & Texas & 0.000079 & 26 & Alabama & 0.000149 \\
3 & Nebraska & 0.000084 & 27 & Florida & 0.000153 \\
4 & New Mexico & 0.000088 & 28 & North Carolina & 0.000155 \\
5 & Virginia & 0.000092 & 29 & Tennessee & 0.000159 \\
6 & New Jersey & 0.000100 & 30 & Oregon & 0.000168 \\
7 & Minnesota & 0.000109 & 31 & Washington & 0.000169 \\
8 & Oklahoma & 0.000110 & 32 & Arkansas & 0.000178 \\
9 & California & 0.000113 & 33 & New Hampshire & 0.000178 \\
10 & Vermont & 0.000115 & 34 & South Carolina & 0.000180 \\
11 & Missouri & 0.000116 & 35 & Utah & 0.000186 \\
12 & Iowa & 0.000118 & 36 & Idaho & 0.000193 \\
13 & Maryland & 0.000118 & 37 & Montana & 0.000200 \\
14 & South Dakota & 0.000119 & 38 & Rhode Island & 0.000219 \\
15 & Colorado & 0.000120 & 39 & Arizona & 0.000219 \\
16 & North Dakota & 0.000124 & 40 & Kentucky & 0.000232 \\
17 & Maine & 0.000125 & 41 & Delaware & 0.000235 \\
18 & Conneticut & 0.000125 & 42 & Ohio & 0.000243 \\
19 & Illinois & 0.000132 & 43 & Wyoming & 0.000254 \\
20 & Georgia & 0.000134 & 44 & Nevada & 0.000294 \\
21 & Pennsylvania & 0.000141 & 45 & Massachusetts & 0.000308 \\
22 & Kansas & 0.000142 & 46 & Indiana & 0.000312 \\
23 & Mississippi & 0.000146 & 47 & Michigan & 0.000776 \\
24 & Wisconsin & 0.000147 & 48 & West Virginia & 0.001625 \\
\hline
\end{tabular}

"Cyclical variability is defined as the variance of the fourth difference of the log of the first difference, i.e. $(1-\mathrm{B})\left(1-\mathrm{B}^{4}\right)$

individual industry $i$ in the national employment. ${ }^{10}$ Weighting the industries in a particular state according to the national average eliminates the direct effect of the industrial composition in the state. The results of this reweighted framework are presented in Table 2. Although the differences between states are diminished, substantial differences remain. The highest variance now is about 9 times the lowest variance. The rankings of some states change substantially because of differences in the two weighting methods. Pennsylvania moved from 21 st to 7 th place, and New Mexico from 4th to 29th place. These changes indicate that the industrial structures in these states were different from the national structure.

\section{Empirical Results}

The adjusted regional cyclical variances were used to test the four hypotheses outlined above. Three regression results are presented. The first covers the entire 19551984 period, the second covers $1955-1969$, and the final regression covers 1970-1984. The sub-periods are reported because of the argument that regional cycles have changed over time, as the regions in the United States have changed in structure and importance. The beginning of 1970 was chosen as the dividing point for the sub-periods because it is the full-sample mid-point. ${ }^{11}$

The full-sample results are reported in Table 3. The $\mathbf{R}^{2}$ of 0.48 indicates a reasonable explanatory power for a cross-sectional analysis. Only two variables, FIRE and nondurable manufacturing, were significant at the 1 percent level. The negative coefficients of both variables indicated that a large share of the FIRE and nondurable manufacturing industries in a particular state lowers the cyclical variance of employment in that state. This supports the hypothesis of a "primary" industry link to cyclical variability. If the key "export" or "primary" industry in a state is stable, local "passive" industries also will tend to be stable. This study found the FIRE and nondurable manufacturing industries to be stable "primary" industries. In states with relatively large components of these "primary" 
Table 2

Weighted Cyclical Employment Variability, by State, 1955-1984", "

\begin{tabular}{llllll}
\hline \hline Rank & State & Variance & Rank & State & Variance \\
\hline 1 & New York & 0.0000649 & 25 & New Hampshire & 0.0001499 \\
2 & Texas & 0.0000860 & 26 & Colorado & 0.0001571 \\
3 & Virginia & 0.0000889 & 27 & Arkansas & 0.0001582 \\
4 & New Jersey & 0.0000963 & 28 & Florida & 0.0001586 \\
5 & Conneticut & 0.0000994 & 29 & New Mexico & 0.0001623 \\
6 & Vermont & 0.0001062 & 30 & Kansas & 0.0001691 \\
7 & Pennsylvania & 0.0001095 & 31 & Rhode Island & 0.0001815 \\
8 & Nebraska & 0.0001108 & 32 & Ohio & 0.0001839 \\
9 & Maine & 0.0001117 & 33 & Delaware & 0.0001873 \\
10 & Illinois & 0.0001147 & 34 & Utah & 0.0001892 \\
11 & Minnesota & 0.0001178 & 35 & Oregon & 0.0001920 \\
12 & Missouri & 0.0001190 & 36 & Washington & 0.0001970 \\
13 & Maryland & 0.0001210 & 37 & South Dakota & 0.0001987 \\
14 & Oklahoma & 0.0001217 & 38 & Kentucky & 0.0002064 \\
15 & Wisconsin & 0.0001229 & 39 & Indiana & 0.0002181 \\
16 & North Carolina & 0.0001232 & 40 & West Virginia & 0.0002191 \\
17 & Louisiana & 0.0001263 & 41 & North Dakota & 0.0002280 \\
18 & California & 0.0001269 & 42 & Arizona & 0.0002323 \\
19 & Iowa & 0.0001301 & 43 & Idaho & 0.0002408 \\
20 & Georgia & 0.0001325 & 44 & Massachusetts & 0.0002694 \\
21 & Mississippi & 0.0001348 & 45 & Wyoming & 0.0002919 \\
22 & South Carolina & 0.0001363 & 46 & Montana & 0.0002946 \\
23 & Alabama & 0.0001368 & 47 & Nevada & 0.0003636 \\
24 & Tennessee & 0.0001380 & 48 & Michigan & 0.0006046 \\
\hline \hline
\end{tabular}

"Cyclical variability is defined as the variance of the fourth difference of the $\log$ of the first difference, i.e. (1-B)(1-B4) \#The weight is the average size of each industry in the national employment.

\section{Table 3}

Cross-sectional Regression Results, Across States, 1955-1984

\begin{tabular}{lcc}
\hline \hline $\begin{array}{l}\text { Sector } \\
\text { Variables }\end{array}$ & $\begin{array}{c}\text { Parameter } \\
\text { Estimate }\end{array}$ & t-Statistic \\
\hline 1. Constant & -1.475 & -2.662 \\
2. FIRE & -1.097 & -3.731 \\
3. Durable & & \\
Manufacturing & 0.164 & 1.161 \\
4. Nondurable & & -1.736 \\
Manufacturing & -0.545 & -1.624 \\
5. Mining & -0.061 & -0.399 \\
6. Sunbelt & 0.055 & 0.024 \\
7. Growth Rate & 0.002 & -0.819 \\
8. Export Share & -0.126 & \\
\hline
\end{tabular}

$\mathrm{N}=48$

$R^{2}=.4799$

Adjusted $\mathrm{R}^{2}=.3888$ 
industries the remaining industries also will be stable over the business cycle. It must be remembered that this result was not due to the fact that some states had large shares of stable industries, compared to other states, as the regional variability measure was adjusted for the industry structure. Instead this result reflects the indirect spill-over effect of regional stability if the primary sectors are stable.

Although stable industries support the "primary" industry argument, unstable industries do not support the hypothesis. Durable manufacturing entered the equation with an insignificant positive coefficient, mining with a marginally significant negative sign. This lack of support for the hypothesis might be due to a failure of mining and durable manufacturing to serve as appropriate proxies for the hypothesis. Either these industries are not unstable across states, or a further division into more detailed SIC classifications might lead to different results.

None of the other hypotheses was supported by the entire period sample. However, this lack of support might be due to a high multicollinearity, as indicated by simple correlations. For example, if the FIRE industry is eliminated from the regression the export share of manufacturing enters with a significant negative sign. ${ }^{12}$ This indicates that states with high export dependence have lower cyclical variances. States with high dependence on exports are insulated from domestic variability through a low or negative covariance between international and domestic conditions. Thus when domestic demands for products fall, international demands increase and make up for the decline in domestic demand. This process leads to a higher stability in export dependent states.

Another reason that some of the hypotheses might not be supported by the results fo the regression could be unstable coefficients over time. To investigate whether the changing regional structure in the United States has led to changes in regional variability, the sample period was divided into two 15 -year sub-periods. ${ }^{13}$

Table 4 shows the results for the first sub-period. The $\mathrm{R}^{2}$ for that period was 0.60 , which was higher than that for the entire period. The results were similar to those for the full period in that two stable "primary" industries, FIRE and nondurable manufacturing, entered significantly. In the earlier period the growth rate also entered the regression significantly. This supports the 1960 hypothesis of Borts that high growth states are less sensitive to cyclical fluctuations due to more optimal production patterns. The mining industry entered significantly, but with a sign opposite the expected one. This probably was due to its high correlation with nondurable manufacturing. ${ }^{14}$ When nondurable manufacturing was dropped from the equation the mining sector switched signs. ${ }^{15}$

Results for the more recent sub-period are shown in
Table 5. Again the stable "primary" industries entered significantly, although the estimated coefficients were not as high as those for the earlier period. The export share of manufacturing also was a significant variable, indicating that states with high dependence on exports are likely to have lower cyclical variability. It is interesting to note that a common belief is that high state dependence on exports can be detrimental to the stability of employment. This finding contradicts that belief, and suggests that states with high export dependence do not import external business cycle variability. Instead, the external influence provides increased stability of in-state employment.

\section{Conclusions}

The findings suggest that states with low cyclical variation have large proportions of FIRE and nondurable manufacturing industries in their industry mixes. Even when cyclical variation is adjusted for the direct effect of the industry composition, there remains an indirect effect of the "primary" to "local" industry type envisioned by Vining (1946a, 1946b). In addition to this indirect effect of the industry structure, a closer look at temporal subperiods indicates that high growth rates and export shares reduce the cyclical variability of employment in a state.

It is believed that this research provides useful insights into the problems of designing functional regional stabilization programs. The industrial structure of the particular state, and its export sector are important factors to consider in designing regional counter-cyclical stabilization programs. It is crucial for regional policy makers to realize that optimal regional economic policies will differ between states, according to the sources of their economic instabilities and the cycles inherent in the industrial composition of the states. Therefore, a state should be hesitant to adopt a stabilization program from another state. A particular state will have a "natural" cyclical variation stemming from its industrial composition, growth rate and the export share of its manufacturing. Although the actual business cycle of a state can be altered to be higher or lower than the "natural" regional cycle by adopting regional policy measures, the effectiveness of such measures is constrained by the "natural" cycle of the region. Thus the success of particular policy measures has to be measured by comparing actual outcomes to the "natural" cycle, not by comparing the actual cycle to actual cycles of other states. For example, comparing the performance of a state such as Massachusetts to that of the nation as a whole is not possible unless the direct and indirect effects of the industry structure are taken into account. Evaluating the regional stabilization policy used in Massachusetts will be impossible unless allowance is made for inherent differ- 
Table 4

Cross-sectional Regression Results, Across States, 1955-1969

\begin{tabular}{llc}
\hline $\begin{array}{l}\text { Sector } \\
\text { Variables }\end{array}$ & $\begin{array}{c}\text { Parameter } \\
\text { Estimate }\end{array}$ & t-Statistic \\
\hline 1. Constant & -0.942 & -1.457 \\
2. FIRE & -1.224 & -3.395 \\
3. Durable & & 0.798 \\
$\quad$ Manufacturing & 0.135 & -6.314 \\
4. Nondurable & & -2.194 \\
Manufacturing & -0.930 & -1.186 \\
5. Mining & -0.103 & -2.361 \\
6. Sunbelt & -0.193 & -0.646 \\
7. Growth Rate & -0.219 & -0.123 \\
8. Export Share & & \\
\hline \hline
\end{tabular}

$\mathrm{N}=48$

$\mathbf{R}^{2}=.6031$

Adjusted $\mathbf{R}^{2}=.5336$

Table 5

Cross-sectional Regression Results, Across States, 1970-1984

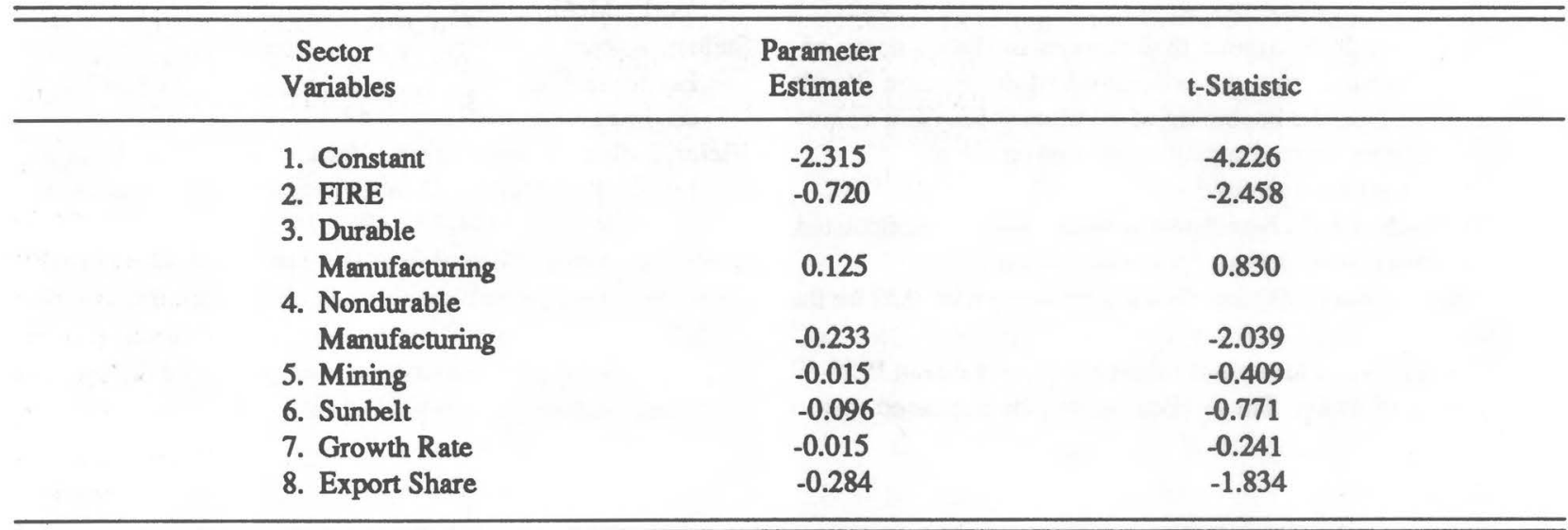

$\mathrm{N}=48$

$R^{2}=0.3243$

Adjusted $\mathrm{R}^{2}=0.2061$

ences in the cyclical variability in Massachusetts and that in the nation in general. The procedure reported in this paper includes a preliminary attempt at modeling such a "natural" cyclical variability. Future research should focus on analyzing particular economic policies against a "natural" equilibrium to evaluate the benefits and costs of these policies.

\section{Notes}

${ }^{1}$ The theories discussed in this paper were selected on the basis of data availability.

${ }^{2}$ This theory obviously is analogous to international trade theories, where a high dependence on export sectors could lead a country to passively adopt foreign business cycles. 
${ }^{3}$ The choice of NBER business cycle definitions for all states may not reflect fully differences in cyclical peaks in various states. However, due to a lack of reliable dating of business cycles across states, this was the only available dating procedure. The full sample growth rates dated peak employment from 1957:3 to 1981:3. The early sub-period dated peak growth rates from 1957:3 to 1960:2, and the latter sub-period used peak growth rates from 1973:4 to 1981:3.

${ }^{4}$ See, for example, Mitchell (1951).

SThe Sun-belt states are: Alabama, Arizona, California, Florida, Georgia, Louisiana, Mississippi, New Mexico, Nevada and Texas.

The export share of manufacturing was taken from the Annual Survey of Manufactures 1975-1976, and is a percentage share of the value of exports or total value of shipments in 1976.

'The employment data include monthly data for $\mathbf{4 8}$ states (excluding Alaska and Hawaii). To create quarterly values of employment the averages of the appropriate months were calculated. The industries used in the calculation of cyclical variability were: mining, construction, manufacturing, transportation, trade, FIRE, services and government.

This procedure currently is used frequently in the business cycle literature. See, for example, Norrbin and Schlagenhauf (1988).

Note that this is not a feature peculiar to the weighting system employed in this paper; it would be true for any weighting system. (1960).

${ }^{10}$ This type of re-weighting was first suggested by Borts

"It also could be argued that changes in the economy occurred at this time, with the breakdown of the Bretton Woods exchange system, the beginning of oil price shocks and a slowdown of military expenditures for the Vietnam War.

${ }^{12}$ The t-statistic was -1.63 .

${ }^{13}$ For each of the sub-periods the variances were recalculated, using the same procedure as for the full sample.

${ }^{14}$ The Pearson simple correlation coefficient was -0.55 for the 48 states.

${ }^{15}$ The mining industry was relatively more stable in 1955-69 than during 1970-84. The cyclical variability increased almost tenfold between the two periods.

\section{References}

Borts, George. "Regional Cycles of Manufacturing Employment in the United States, 1914-1953." Journal of the American Statistical Association, 1960, 55:151-211.

Browne, Lynn. "Regional Industry Mix and the Business Cycle." New England Economic Review, Nov./Dec. 1978: 35-53.

Goldstein, Harvey. "The Changing International Division of Labor and Regional Employment Cycles in the U.S." The Review of Regional Studies, Winter, 1986: 31-43.

Hayek, Friedrich von, Prices and Production, New York: Augustus M. Kelley, 1931.

Howland, Marie. "Age of Capital and Regional Business Cycles." Growth and Change, April 1984: 29-37.

Mitchell, Wesley. "What Happens During Business Cycles." National Bureau of Economic Research, 1951.

Nelson, Charles R. and Charles I. Plosser. "Trends and Random Walks in Macroeconomic Time Series: Some Evidence and Implications." Journal of Monetary Economics, September 1982: 139-162.

Norrbin, Stefan C. and DonE. Schlagenhauf. "An Inquiry into the Sources of Macroeconomic Fluctuations." Jourmal of Monetary Economics, July 1988: 43-70.

Schumpeter, Joseph, Business Cycles: A Theoretical, Historical, and Statistical Analysis of the Capitalistic Process. New York: MoGraw-Hill, 1939.

Steiner, Robert L. "Discussion of Interregional Variations in Economic Fluctuations." American Economic Review, Proceedings, May 1949: 131-148.

Victor, Richard B. and Georges Vernez. Employment Cycles in Local Labor Markets. Santa Monica, CA: The Rand Corporation, R-2647-EDA/RC, 1981.

Vining, Rutledge. "Location of Industry and Regional Patterns of Business-Cycle Behavior." Econometrica, 14, 1946a: 37 68.

"The Region as a Concept in Business-Cycle Analysis." Econometrica, 14, 1946b: 201-218. 